\title{
Etiology, Management, and Outcome of the Budd-Chiari Syndrome
}

Sarwa Darwish Murad, MD, PhD; Aurelie Plessier, MD; Manuel Hernandez-Guerra, MD; Federica Fabris, MD; Chundamannil E. Eapen, MD; Matthias J. Bahr, MD; Jonel Trebicka, MD; Isabelle Morard, MD; Luc Lasser, MD; Joerg Heller, MD; Antoine Hadengue, MD; Philippe Langlet, MD; Helena Miranda, MD, PhD; Massimo Primignani, MD; Elwyn Elias, MD, BSc, FRCP; Frank W. Leebeek, MD, PhD; Frits R. Rosendaal, MD, PhD; Juan-Carlos Garcia-Pagan, MD, PhD; Dominique C. Valla, MD, PhD; and Harry L.A. Janssen, MD, PhD, for EN-Vie (European Network for Vascular Disorders of the Liver)*

Background: The Budd-Chiari syndrome (BCS) is hepatic venous outflow obstruction. What is known about the syndrome is based on small studies of prevalent cases.

Objective: To characterize the causes and treatment of incident BCS.

Design: Consecutive case series of patients with incident BCS, enrolled from October 2003 to October 2005 and followed until May 2006.

Setting: Academic and nonacademic hospitals in France, Spain, Italy, Great Britain, Germany, Belgium, the Netherlands, Portugal, and Switzerland.

Patients: Persons older than 16 years with definite hepatic outflow obstruction diagnosed by imaging. Persons with hepatic outflow obstruction due to heart failure, sinusoidal obstruction syndrome, cancer, or liver transplantation were excluded.

Measurements: Signs and symptoms; laboratory and imaging findings; diagnosis; treatment; and overall, transplantation-free, and intervention-free survival.

Results: 163 incident cases of BCS were identified. Median follow-up was 17 months (range, 0.1 to 31 months). Most patients (84\%) had at least 1 thrombotic risk factor, and many (46\%) had more than 1 ; the most common was myeloproliferative disorders (49\% of 103 tested patients). Patients were mainly treated with anticoagulation (140 patients [86\%]), transjugular intrahepatic portosystemic shunting (56 patients [34\%]), or liver transplantation (20 patients [12\%]), and 80 patients (49\%) were managed noninvasively. Only 3 patients underwent surgical shunting. The survival rate was $87 \%(95 \% \mathrm{Cl}, 82 \%$ to $93 \%)$ at 1 year and $82 \%\left(\mathrm{Cl}_{\text {, }}\right.$ $75 \%$ to $88 \%$ ) at 2 years.

Limitation: Treatment was not standardized across all centers, and data on important clinical variables were missing for some patients.

Conclusion: Most patients with BCS have at least 1 thrombotic risk factor, and many have more than 1; myeloproliferative disorders are most common. One- and 2-year survival rates are good with contemporary management, which includes noninvasive therapies (anticoagulation and diuretics) and invasive techniques. Transjugular intrahepatic portosystemic shunting seems to have replaced surgical shunting as the most common invasive therapeutic procedure.

Primary Funding Source: Fifth Framework Programme of the European Commission.

Ann Intern Med. 2009;151:167-175

www.annals.org

For author affiliations, see end of text.

* For a list of the EN-VIE Investigators, see the Appendix (available at www.annals.org).

$\mathrm{T}$ he Budd-Chiari syndrome (BCS) is a rare but clinically challenging disorder defined as obstruction of hepatic venous outflow anywhere from the small hepatic veins to the suprahepatic inferior vena cava (1). In the Western world, thrombosis is the most common cause. Classically, a previously healthy young woman presents with sudden onset of abdominal pain, ascites, and hepatomegaly, but many variations to this clinical presentation exist. Patients frequently have an underlying thrombotic disorder. Studies have suggested that one quarter of patients have multiple thrombotic risk factors $(2,3)$. Therapeutic options include medical treatments (anticoagulants and diuretics) and invasive management (thrombolysis, percutaneous transluminal angioplasty, transjugular intrahepatic portosystemic shunting [TIPS], surgical portosystemic shunting, and orthotopic liver transplantation [OLT]) $(4,5)$.

The Budd-Chiari syndrome is uncommon, with an incidence estimated at 1 in 2.5 million persons per year (6), and current knowledge about its etiology and prognosis is based on small, older studies of prevalent cases. Thus, what we know about the disease is influenced by survival bias (patients must survive to be included as prevalent cases) and does not incorporate experience with current

treatments and their effects $(7-11)$. We therefore performed a large prospective multicenter study of patients with recently diagnosed BCS who were treated with contemporary therapies.

\section{Methods}

\section{Study Design}

We studied a case series of consecutive patients with incident BCS, identified in academic and large regional hospitals in 9 European countries (France, Spain, Italy, Great Britain, Germany, Belgium, the Netherlands, Portugal, and Switzerland) between October 2003 and October 2005 and followed them until May 2006 (study closure);

See also:

Print

Editors' Notes . . . . . . . . . . . . . . . . . . . . . 168

Web-Only

Appendix

Conversion of graphics into slides 
ARTICLE Etiology, Management, and Outcome of the Budd-Chiari Syndrome

\section{Context}

Much of what is known about hepatic venous outflow obstruction (the Budd-Chiari syndrome) comes from older studies of previously diagnosed cases.

\section{Contribution}

Among 163 patients with newly diagnosed Budd-Chiari syndrome who were prospectively followed at medical centers in Europe, most had identifiable risk factors for clot, most commonly myeloproliferative disorders. About half of patients were managed noninvasively with diuretics and anticoagulation, and half were managed with transjugular shunting, recanalization, and liver transplantation; survival rates were good.

\section{Caution}

Treatment and data collection were not standardized across medical centers.

\section{Implication}

With contemporary management, survival among patients with the Budd-Chiari syndrome is better than previously described. death; or for patients lost to follow-up, date of last visit. All national and, if necessary, local ethics committees approved the study, and all patients provided written informed consent to participate.

We defined BCS as hepatic outflow obstruction regardless of the cause or level of obstruction, which could occur from the small hepatic veins to the entrance of the inferior vena cava into the right atrium (1). Sinusoidal obstruction syndrome (previously known as veno-occlusive disease) was excluded from this definition. All consecutive patients older than 16 years with newly diagnosed BCS who met this case definition were enrolled if the evidence for BCS was unambiguous and established by radiographic imaging (ultrasonography, computed tomography, magnetic resonance imaging, or venography). Patients were excluded if outflow obstruction occurred in the setting of heart failure, OLT, or hepatobiliary cancer.

\section{Data Collection}

To standardize patient management, all participating centers received monitoring guidelines instructing providers what information to obtain when and advising them about general indications for invasive procedures, such as portosystemic shunting and OLT. Data were collected at baseline; weeks 1 to 4; months 2, 3, 6, 9, 12, 18 and 24; death; and significant clinical events, defined as clinical deterioration (any new hospital admission or first development or recurrence of massive ascites, spontaneous bacterial peritonitis, hepatorenal syndrome, variceal bleeding, or hepatic encephalopathy), new radiographic liver study, and new BCS-related intervention. One investigator per country used a structured questionnaire to obtain all data from standardized review of medical charts. For purposes of data quality assessment, 1 investigator periodically reviewed and monitored data. If data were missing or seemed erroneous, the original charts were reviewed. Copies of the original imaging studies were collected and scored by 1 radiologist per country who had special expertise in vascular liver disease.

\section{Laboratory Testing}

At diagnosis, plasma and DNA samples were obtained according to a uniform protocol and sent to a central laboratory (Hôpital Beaujon, Clichy, France) for standardized thrombophilia assessment. Patients were screened for the factor V G1691A mutation (factor V Leiden); the prothrombin gene G20210A mutation; protein S, protein C or antithrombin deficiency; myeloproliferative disorders (MPDs) and the JAK2 V617F mutation; antiphospholipid antibodies, hyperhomocystinemia, and the MTHFR C677T mutation; paroxysmal nocturnal hemoglobinuria; and Behçet disease. Because deficiencies of protein $\mathrm{C}$ and $\mathrm{S}$ and antithrombin can be acquired through hepatocellular dysfunction or use of anticoagulants or oral contraceptives, a deficiency was considered hereditary if only 1 of the 3 proteins was deficient (isolated deficiency), the abovementioned drugs were not used, and the bilirubin level was less than 2 times the upper limit of normal. In addition, for protein $S$ deficiency, patients could not also have the factor V Leiden mutation or anticardiolipin IgG antibodies, because these can influence protein $S$ levels. An expert who was not involved in data analysis reviewed each case individually.

\section{Statistical Analysis}

Results are expressed as proportions for categorical variables and as medians and ranges for continuous variables. Actuarial transplantation-free and intervention-free survival rates were calculated by using the Kaplan-Meier method. Variables that for historical or clinical reasons were thought to be associated with invasive interventions were entered individually and then together into a Cox regression analysis to identify which were statistically significant. The assumption of proportionality was verified by taking all variables that were statistically significant in the analysis and including them as time-dependent variables $(\ln ($ variable)*time) in the final model (all $P>0.10)$. Statistical significance was defined as a $P$ value less than 0.05 . All statistical analyses were conducted with SPSS, version 14.0.0 (SPSS, Chicago, Illinois).

\section{Role of the Funding Source}

The EN-Vie project was financially supported by the Fifth Framework Programme of the European Commission (contract "QLG1-CT-2002-01686) and public funding from GIS Maladies Rares (France 2001). The funding agency had no role in the conduct of the study, the inter- 
pretation of the data, or the decision to submit the manuscript for publication.

\section{RESULTS \\ Sample}

Table 1 shows baseline patient characteristics. Of 210 patients in 39 hospitals, 47 were excluded (date of diagnosis fell outside the study period $[n=16]$; diagnosis of BCS not confirmed $[n=14]$; underlying cancer $[n=7]$; BCS diagnosed only by liver biopsy $[n=2]$; secondary BCS in the context of cirrhosis or liver tumor due to other underlying liver disease $[n=6]$; loss to follow-up after informed consent was obtained $[n=1]$; and portal vein thrombosis only, without involvement of the hepatic veins $[n=1]$ ), leaving 163 eligible patients. The median age at diagnosis was 38 years (range, 16 to 83 years); 93 patients (57\%) were female, and $87 \%$ were white. Median follow-up was 17.1 months (range, 0.1 to 31 months).

\section{Clinical Features}

Prominent clinical features were ascites (83\%) and abdominal pain $(61 \%)$. One half of the patients had recent onset of symptoms ( $<1$ month). In 5 patients, all of whom were asymptomatic, BCS was found incidentally. Two hundred twenty-seven imaging studies were performed to establish the diagnosis; ultrasonography was most commonly used (88 patients [39\%]), followed by computed tomography (82 patients [36\%]), magnetic resonance imaging (36 patients [16\%]), and venography (21 patients [9\%]). The most prevalent feature on imaging was hepatomegaly $(67 \%)$. Hepatic outflow obstruction involved the hepatic veins in $49 \%$ of patients, the inferior vena cava in $2 \%$, and both in $49 \%$. The inferior vena cava was occluded by a membrane (thought to be a vestige of organized clot) in only 2 patients. Concurrent obstruction in the portal venous system was found in 30 patients (18\%); locations of obstruction included the portal (11 patients), superior mesenteric (2 patients), and splenic veins (2 patients) or combinations of the 3 (15 patients). Thirty-nine patients (24\%) underwent liver biopsy at diagnosis; histologic features of sinusoidal congestion (25 patients [64\%]), hepatocellular necrosis (13 patients [33\%]), and fibrosis (23 patients [59\%]) were found, and significant heterogeneity was often present within the same specimen. Evidence of cirrhosis was present in 7 patients (18\%).

\section{Thrombotic Risk Factors}

Table 2 summarizes thrombotic risk factors. Almost all patients (160 [98\%]) were screened for underlying thrombotic disorders; 20 patients were anticoagulated at the time of diagnosis before testing. At least 1 thrombophilic disorder was identified in 135 patients $(84 \%)$, and $74(46 \%)$ had more than 1 disorder. The most common underlying disease was an MPD, which was found in 50 (49\%) of the 103 patients who underwent bone marrow biopsy $(n=93)$, red cell mass measurement $(n=29)$, or
Table 1. Patient Characteristics at Diagnosis

\begin{tabular}{|c|c|}
\hline Characteristic & Data \\
\hline \multicolumn{2}{|l|}{ Clinical, $n(\%)^{*}$} \\
\hline Ascites & $135(83)$ \\
\hline Abdominal pain & $99(61)$ \\
\hline Esophageal varicest & $45(58)$ \\
\hline Hepatic encephalopathy & $15(9)$ \\
\hline $\begin{array}{l}\text { Type } 1 \text { hepatorenal } \\
\text { syndrome }\end{array}$ & $12(7)$ \\
\hline \multicolumn{2}{|l|}{$\begin{array}{l}\text { Duration of symptoms before } \\
\text { diagnosis }\end{array}$} \\
\hline$<1 \mathrm{mo}$ & $82(50)$ \\
\hline $1-6 \mathrm{mo}$ & $56(34)$ \\
\hline $6 \mathrm{mo}$ & $23(14)$ \\
\hline \multicolumn{2}{|l|}{ Acuity of symptoms§ } \\
\hline Acute & $43(26)$ \\
\hline Chronic & $33(20)$ \\
\hline Both & $87(53)$ \\
\hline \multicolumn{2}{|l|}{ Laboratory\| } \\
\hline ALT/ULN ration & $1.4(0.3-294.4)$ \\
\hline Albumin level, $g / L$ & $34(17-51)$ \\
\hline \multicolumn{2}{|l|}{ Bilirubin level } \\
\hline$\mu \mathrm{mol} / \mathrm{L}$ & $31(4-325)$ \\
\hline$m g / d L$ & $1.8(0.23-19.0)$ \\
\hline \multicolumn{2}{|l|}{ Creatinine level } \\
\hline$\mu \mathrm{mol} / \mathrm{L}$ & $80(36-589)$ \\
\hline$m g / d L$ & $0.91(0.41-6.7)$ \\
\hline \multicolumn{2}{|l|}{ Prothrombin time ${ }^{* *}$} \\
\hline Seconds & $18.1(11.4-61.7)$ \\
\hline International normalized ratio & $1.4(1.0-10.9)$ \\
\hline Quick time, \% & $64(7-100)$ \\
\hline \multicolumn{2}{|l|}{ Radiographic, $n(\%)+\dagger$} \\
\hline Caudate lobe hypertrophy & $118(72)$ \\
\hline Hepatomegaly & $109(67)$ \\
\hline Splenomegaly & $85(52)$ \\
\hline \multicolumn{2}{|l|}{ Location of outflow obstruction } \\
\hline Hepatic veins & $80(49)$ \\
\hline Inferior vena cava & $4(2)$ \\
\hline Both & 79 (49) \\
\hline \multicolumn{2}{|l|}{$\begin{array}{l}\text { Number of hepatic veins } \\
\text { involved }\end{array}$} \\
\hline 1 & $15(9)$ \\
\hline 2 & $15(9)$ \\
\hline 3 & $129(79)$ \\
\hline Portal vein occlusion & $30(18)$ \\
\hline \multicolumn{2}{|l|}{ Histologicキ¥ } \\
\hline Sinusoidal congestion & $25(64)$ \\
\hline Fibrosis & $23(59)$ \\
\hline Hepatocellular necrosis & $13(33)$ \\
\hline Cirrhosis & $7(18)$ \\
\hline
\end{tabular}

ALT $=$ alanine aminotransferase; ULN $=$ upper limit of normal.

* Data were available for all 163 patients in the sample.

† 77 patients underwent esophagogastroduodenoscopy.

\# Defined as a decrease in creatinine clearance $\geq 50 \%$ to a value $<20 \mathrm{~mL} / \mathrm{min}$ or an increase in serum creatinine level $\geq 2$-fold to $\geq 221 \mathrm{mmol} / \mathrm{L}$ in $<2$ weeks. $\S$ By predefined criteria (11), "acute" is abdominal pain, ALT level $>5$ times the ULN, and liver cell loss at biopsy (if available); "chronic" is previous symptoms or hospitalizations, splenomegaly, atrophy or hypertrophy complex of liver lobes, and centrilobular fibrosis or cirrhosis at biopsy (if available).

$\|$ Data are expressed as the median (range).

I ALT level divided by the laboratory-specific ULN. This ratio standardizes expression of elevation across medical centers.

** Measures exclude 20 patients who were anticoagulated at the time of diagnosis. †† Data were available for all 163 patients. Patients may have had more than 1 imaging study. Findings are reported by detection according the following hierarchy: magnetic resonance imaging, computed tomography, ultrasonography, venography.

¥¥ Data were available for 39 patients. 


\section{Table 2. Thrombotic Risk Factors*}

\begin{tabular}{|c|c|}
\hline Risk Factor & $\begin{array}{l}\text { Patients With } \\
\text { Risk Factor, } \\
n / n(\%)\end{array}$ \\
\hline \multicolumn{2}{|l|}{$\begin{array}{c}\text { Thrombophilia } \\
\text { Inherited } \dagger\end{array}$} \\
\hline Any inherited disorder & $32 / 154(21)$ \\
\hline Factor V Leiden G1691A mutation & $18 / 147(12)$ \\
\hline Prothrombin gene G20210A mutation & $5 / 144(3)$ \\
\hline Protein C deficiency $¥$ & $5 / 117(4)$ \\
\hline Protein S deficiency $§ \S$ & $3 / 108(3)$ \\
\hline Antithrombin deficiency $\neq$ & $3 / 112(3)$ \\
\hline \multicolumn{2}{|l|}{ Acquired $t$} \\
\hline Any acquired disorder & $67 / 153(44)$ \\
\hline Antiphospholipid antibodies & $37 / 150(25)$ \\
\hline Hyperhomocysteinemia|| & $28 / 129(22)$ \\
\hline Paroxysmal nocturnal hemoglobinuria & 15/77 (19) \\
\hline Myeloproliferative disorder or JAK2 mutationף & $56 / 143(39)$ \\
\hline Any myeloproliferative disorder & $50 / 103(49)$ \\
\hline Polycythemia vera & 27 \\
\hline Essential thrombocythemia & 9 \\
\hline Idiopathic myelofibrosis & 2 \\
\hline Unclassified & 11 \\
\hline Occult** & 1 \\
\hline JAK2 V617F mutation & $35 / 121(29)$ \\
\hline Hormonal factors (women only)t & $35 / 93(38)$ \\
\hline Oral contraceptive use & $31 / 93(33)$ \\
\hline Pregnancy within 3 mo before diagnosis & $6 / 93(6)$ \\
\hline Systemict & $37 / 163(23)$ \\
\hline Connective tissue disease & 10 \\
\hline Inflammatory bowel disease & 8 \\
\hline Behçet disease & 4 \\
\hline Sarcoidosis & 2 \\
\hline Vasculitis & 1 \\
\hline Dehydration & 5 \\
\hline Othertt & 10 \\
\hline
\end{tabular}

* Not all patients underwent every test.

† Patients were positive for at least 1 factor.

₹ Deficiency was diagnosed as nonacquired only if 1 protein was deficient, the result occurred in the absence of use of anticoagulants or oral contraceptives, and the patient did not have liver dysfunction (bilirubin level $<2$ times the upper limit of normal).

§ Additional criteria for diagnosing protein $S$ deficiency as nonacquired were absence of the factor V Leiden mutation and anticardiolipin IgG antibodies.

$\|$ Defined as elevated plasma homocysteine level $(>15 \mu \mathrm{mol} / \mathrm{L})$ or homozygosity for the MTHFR C677T mutation.

I Diagnosis made by evidence of myeloproliferative disorder on bone marrow biopsy, spontaneous colony formation on cultures, or presence of the JAK2 mutation.

${ }^{* *}$ Negative biopsy result but positive culture result.

†† Intra-abdominal infection, sepsis, or spontaneous bacterial peritonitis.

colony cultures $(n=41)$. The $J A K 2 \mathrm{~V} 617 \mathrm{~F}$ mutation was found in 35 of 121 tested patients (29\%), of whom 27 had a mutational load less than $50 \%$ and 4 had a mutational load greater than $75 \%$; mutational load could not be calculated in 4 patients. Twenty-eight of the 35 JAK2-positive patients (80\%) already had features of MPD on bone marrow biopsy; the biopsy result was negative in 4 patients, and biopsy was not performed in 3 patients.

The factor V Leiden mutation was found in 18 tested patients $(12 \%)$, and the prothrombin gene mutation was found in 5 tested patients (3\%). Many patients with the factor $\mathrm{V}$ Leiden mutation had additional thrombotic risk factors: oral contraceptive use (3 patients), oral contracep- tive use plus MPD (2 patients) or antiphospholipid antibodies (1 patient), MPD alone (3 patients), MPD plus hyperhomocystinemia (1 patient) or antiphospholipid antibodies ( 1 patient), protein $\mathrm{C}$ deficiency (1 patient), antiphospholipid antibodies (1 patient), and pregnancy (1 patient). Patients with prothrombin gene mutations also had additional thrombotic risk factors (oral contraceptives plus MPD [1 patient] or antiphospholipid antibodies [1 patient]) or hyperhomocystinemia [1 patient]; MPD alone [1 patient]; or MPD, antiphospholipid antibodies, and irritable bowel disease [1 patient]). Hyperhomocystinemia, defined as elevated plasma homocysteine levels or homozygosity for the MTHFR C677T mutation (genotype 677 TT), was detected in 28 tested patients $(22 \%)$, of whom $79 \%$ had additional thrombotic risk factors. Among tested patients, isolated protein $\mathrm{C}$ deficiency was present in 5 (4\%), protein $S$ deficiency in $3(3 \%)$, and antithrombin deficiency in $3(3 \%)$.

\section{Management}

Eighty-three patients (51\%) underwent an invasive intervention, $80(49 \%)$ were managed without an invasive intervention, and $13(8 \%)$ received no specific treatment (Figure 1). Ten of the 13 untreated patients had no $(n=$ $3)$ or mild $(n=7)$ symptoms and nearly normal bilirubin levels (median, $19 \mu \mathrm{mol} / \mathrm{L}$ [range, 8 to $52 \mu \mathrm{mol} / \mathrm{L}$ ]). All of these 10 patients survived and remained ascites-free at a median follow-up of 22.7 months (range, 6.8 to 31.0 months). The remaining 3 untreated patients had severe liver failure, and all of them died within 5 months (range, 1.6 to 4.4 months). The majority of patients received treatment with anticoagulation (140 patients [86\%]) and diuretics (100 patients [61\%]). Twenty patients were already receiving anticoagulation for a median of 27 days (range, 1 to 990 days) before diagnosis of BCS for previous thrombotic events $(n=11)$ or suspected but unconfirmed BCS before the final diagnosis was made $(n=9)$. Only $5(8 \%)$ anticoagulated patients developed variceal bleeding; all cases were nonfatal.

Twenty-two patients underwent thrombolysis $(n=$ $10)$ or percutaneous transluminal angioplasty $(n=14)$ as an initial invasive procedure. Immediate recanalization was achieved in $4(40 \%)$ patients undergoing thrombolysis and $8(57 \%)$ of those undergoing percutaneous transluminal angioplasty. Thirteen patients required subsequent TIPS, and 1 patient deteriorated rapidly and needed OLT 2.8 months later.

Placement of TIPS was attempted in 64 patients (39\%) and was successful in 56 (34\%). Main indications for TIPS were refractory ascites (64\%), liver failure (13\%), and variceal bleeding (5\%). We observed no significant differences in clinical variables between patients in whom TIPS was successful and those in whom it was not, suggesting that failure of placement was largely due to technical issues (data not shown). The approach of the TIPS procedures was through the hepatic vein remnant in $49 \%$ 
of patients and transcaval in 51\%. Shunt dysfunction occurred in 9 patients (18\%) and was successfully treated by TIPS revision in all cases. Polytetrafluoroethylene-covered stents were used in $63 \%$ (35 patients), with a patency rate of $85 \%$. After TIPS, 3 patients (5\%) required OLT.

In contrast to the liberal use of TIPS, surgical shunting (all side-to-side portocaval) was performed in only 3 patients $(2 \%)$. Thrombosis of the surgical shunt occurred in 1 patient, who died 2 months later. The second patient who had surgical shunting continued to have refractory ascites and underwent OLT after 9.8 months. The third patient remained transplant-free.

Twenty patients (12\%) underwent OLT. Indications were fulminant or rapidly progressive liver failure (8 patients), absence of response on previous intervention (5 patients), rescue treatment for fulminant hepatic failure after failed attempt of TIPS (2 patients), intractable variceal bleeding ( 2 patients), refractory ascites ( 2 patients), and the hepatopulmonary syndrome (1 patient). One pa- tient died immediately after OLT because of multiorgan failure (TIPS placement had failed in this patient), and 1 patient died 6.6 months after OLT because of ovarian sarcoma that became evident only after the procedure. All 18 surviving patients were alive and symptom-free at a median follow-up of 19 months after OLT (range, 1.1 to 30.2 months).

\section{Survival and Prognostic Indicators}

Fourteen patients were lost to follow-up after a median of 17.4 months (range, 0.7 to 38.6 months), and 29 patients died a median of 5.5 months after diagnosis (range, 0.1 to 26.3 months). The main causes of death were liver failure (8 patients), multiorgan failure (4 patients), and gastrointestinal bleeding ( 2 patients). Median follow-up for surviving patients was 19.3 months (range, 0.3 to 31 months). Overall survival rates were 90\% (95\% CI, 85\% to $94 \%$ ) at 6 months, $87 \%$ (CI, $82 \%$ to $93 \%$ ) at 12 months, and $82 \%(\mathrm{CI}, 75 \%$ to $88 \%)$ at 24 months; the

\section{Figure 1. Study flow diagram.}

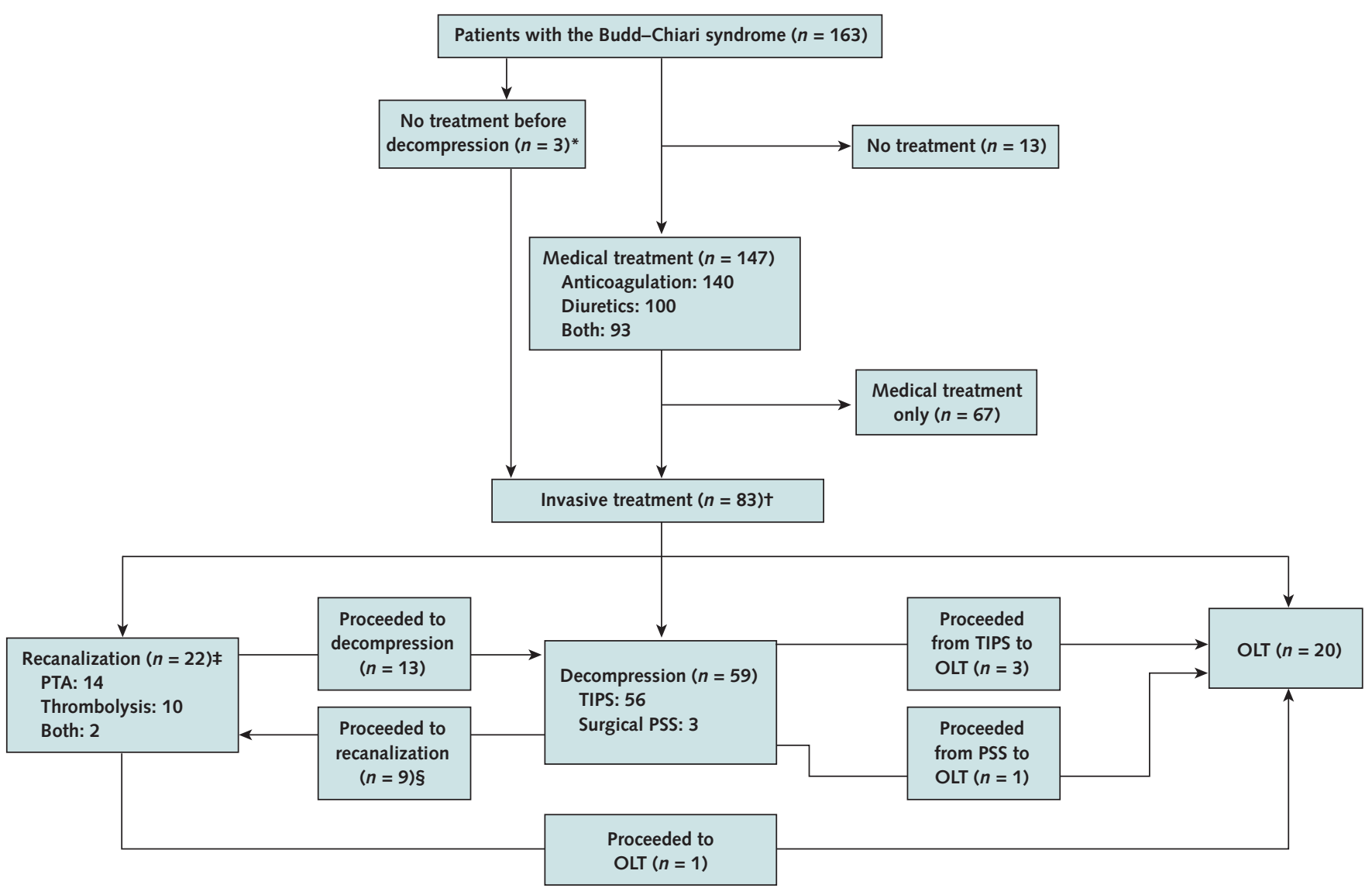

OLT $=$ orthoptic liver transplantation; PSS $=$ portosystemic shunt; PTA = percutaneous transluminal angioplasty; TIPS = transjugular intrahepatic portosystemic shunt.

* 2 patients underwent TIPS, and 1 underwent surgical shunting.

+22 patients proceeded directly to recanalization, 46 proceeded directly to decompression, and 15 proceeded directly to OLT.

¥ Patients can have had $>1$ procedure.

$\S$ Revision of TIPS by recanalization procedures. 


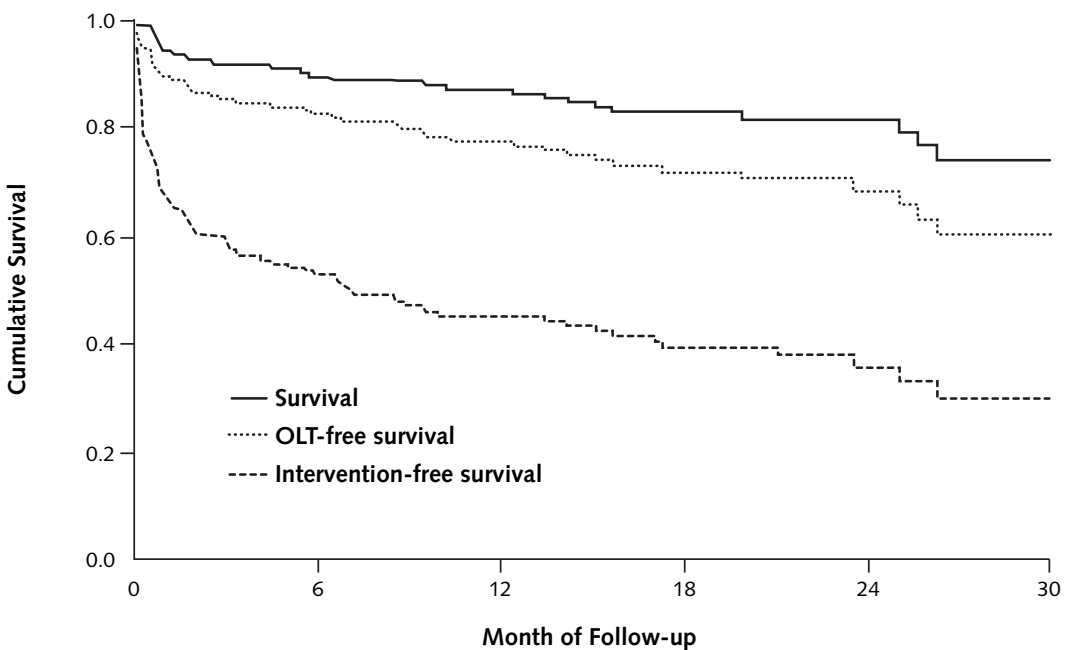

$\begin{array}{cccccccccccc}\begin{array}{c}\text { Patients at risk } \\ \text { Actuarial }\end{array} & 0 & 3 & 6 & 9 & 12 & 15 & 18 & 21 & 24 & 27 & 30 \\ \begin{array}{c}\text { survival, } n \\ \text { OLT-free }\end{array} & 163 & 145 & 141 & 133 & 118 & 94 & 77 & 58 & 36 & 24 & 12 \\ \begin{array}{c}\text { survival, } n \\ \text { Intervention-free } \\ \text { survival, } n\end{array} & 163 & 135 & 130 & 120 & 103 & 80 & 65 & 47 & 28 & 19 & 10 \\ & 163 & 92 & 82 & 70 & 59 & 46 & 36 & 25 & 15 & 8 & 5\end{array}$

OLT $=$ orthoptic liver transplantation

respective OLT-free survival rates were $83 \%(\mathrm{CI}, 77 \%$ to $88 \%$ ), $77 \%$ (CI, $71 \%$ to $84 \%$ ), and $68 \%$ (CI, $60 \%$ to $77 \%)$, and rates of survival without invasive intervention were $52 \%$ (CI, $44 \%$ to $59 \%$ ), $44 \%$ (CI, $36 \%$ to $52 \%$ ), and $35 \%$ (CI, 26\% to 44\%) (Figure 2).

Univariate analyses revealed that patients with ascites and hepatic encephalopathy; higher bilirubin, alanine aminotransferase, and creatinine levels and prothrombin time; and lower albumin levels at diagnosis had higher rates of invasive interventions (Table 3). In multivariable analyses, ascites, male sex, and higher creatinine level were statistically significantly associated with invasive interventions.

\section{Discussion}

This series of 163 incident cases of BCS in 9 western European countries suggests that 1 or more thrombotic risk factors underlie onset of the condition in most patients; that many patients can safely be managed with noninvasive treatments, such as anticoagulation, and that most who cannot can be managed with minimally invasive procedures, such as TIPS; and that survival is now better than previously thought. These findings can be considered more reliable than those of past studies, because our prospective study design reduced the selection and information biases common to previous retrospective studies. In addition, less invasive management options for BCS are now more readily available.
We found that most patients (84\%) had an underlying acquired or inherited thrombophilia and that $46 \%$ had 2 or more thrombotic risk factors; this proportion is almost twice as high as previously reported $(2,3)$. This higher frequency is probably attributable to the fact that we performed a near-complete etiologic work-up; our findings therefore show the appropriateness of a complete thrombophilia work-up in patients with BCS. The fact that $16 \%$ of patients with BCS did not have a known prothrombotic condition highlights the need to identify additional thrombogenic factors in the future, such as those in the fibrinolytic pathway, that might be clinically relevant.

Myeloproliferative disorders were the most prevalent underlying conditions (49\%), in line with previous findings $(12,13)$. These disorders may not be clinically obvious in patients with BCS because concurrent hypersplenism, occult gastrointestinal bleeding, and hemodilution can mask peripheral blood abnormalities (14); bone marrow biopsies are thus often needed when peripheral blood analysis is nondiagnostic. The recently discovered JAK2 V617F mutation has been found in $40 \%$ to $59 \%$ of patients with BCS $(12,15,16)$, which led some to propose that it could be used as a screening test for MPDs. However, we found the JAK2 mutation in only $29 \%$ of 121 tested patients. We believe this discrepancy is largely attributable to selection bias: All previous studies were retrospective, were conducted exclusively in tertiary hepatology or hematology 
centers, and performed $J A K 2$ testing on stored samples. The diagnostic significance of the JAK2 mutation is yet to be determined, but we believe that a hematologic work-up for MPDs should be considered for all patients with BCS, given the high prevalence of MPDs in this group.

The factor V Leiden and prothrombin gene mutations are inherited thrombotic disorders classically associated with BCS. The factor V Leiden mutation was prevalent in $12 \%$ of our predominantly white sample. This is lower than the frequency of $22 \%$ to $31 \%$ reported in earlier studies $(2,3,17,18)$. In comparison, the factor $\mathrm{V}$ Leiden mutation is present in $12 \%$ to $19 \%$ of patients with deep venous thrombosis $(19,20)$ and in $5 \%$ to $8 \%$ of the general white population (21). The prevalence of the prothrombin gene mutation (3\% in our study vs. $2 \%$ in healthy persons [22]) and hyperhomocystinemia (22) did not exceed population frequencies. Selection of the sickest patients in highly specialized centers probably accounts for the discrepancy with older studies of BCS. Moreover, 78\% of patients with the factor V Leiden mutation and $100 \%$ of those with prothrombin gene mutations had at least 1 other identifiable cause of BCS, indicating that the role of these mutations is probably additive to other existing thrombotic disorders.

Most of our patients received treatment with anticoagulation (86\%), followed by TIPS (34\%), and only 3 patients received a surgical portosystemic shunt. This observation reflects how management of BCS has changed over time. Before 2000, surgical shunting was the mainstay of therapy (done in $50 \%$ to $68 \%$ of patients in earlier series
[10]). Transjugular intrahepatic portosystemic shunting has overtaken surgical intervention in frequency, perhaps because the feared complication of shunt occlusion has diminished with the newer polytetrafluorethylene-covered stents, which provide excellent patency $(23,24)$. Although evidence from randomized studies is lacking, we observed good outcomes for patients with BCS who had TIPS and therefore believe that TIPS should be the treatment of choice for patients who do not respond to noninvasive management and for those with refractory ascites and progressive liver dysfunction.

Nearly half of our patients were managed without a radiologic or surgical therapeutic intervention. The time to these interventions, which is used as a surrogate marker for clinical deterioration, seemed to be determined by factors related to patient survival (ascites, male sex, and higher creatinine levels) $(8,10)$. These factors must be further validated in future studies to establish their role in risk stratification and clinical decision making.

We observed excellent short-term survival rates, which were similar to and sometimes better than those observed in earlier retrospective series, in which more aggressive interventions (such as surgical shunting) were used $(8,10)$. In part, this finding is explained by the fact that our study was based on incident cases from both academic and community hospitals; as a result, our analysis was not restricted to the sickest patients, as was the case in previous studies. The fact that $86 \%$ of our patients received anticoagulation, which is associated with the increased long-term survival observed since 1985 (10), and the availability of effective

Table 3. Hazard for Invasive Intervention*

\begin{tabular}{|c|c|c|c|c|}
\hline \multirow[t]{2}{*}{ Predictor } & \multicolumn{2}{|c|}{ Univariate Cox Model } & \multicolumn{2}{|c|}{ Multivariate Cox Model } \\
\hline & Hazard Ratio (95\% Cl) & $P$ Value & Hazard Ratio $(95 \% \mathrm{Cl})$ & $P$ Value \\
\hline Age (per 10-y increase) & $1.08(0.95-1.22)$ & 0.27 & $0.96(0.81-1.12)$ & 0.58 \\
\hline \multicolumn{5}{|l|}{ Sex } \\
\hline Male & $1.38(0.93-2.05)$ & 0.11 & $1.69(1.07-2.66)$ & 0.024 \\
\hline Female & 1.0 (reference) & & 1.0 (reference) & \\
\hline \multicolumn{5}{|l|}{ Ascites } \\
\hline Present & $12.43(3.92-39.36)$ & $<0.001$ & $8.22(1.91-35.36)$ & 0.005 \\
\hline Absent & 1.0 (reference) & & 1.0 (reference) & \\
\hline \multicolumn{5}{|l|}{ Hepatic encephalopathy } \\
\hline Present & $3.89(2.22-6.81)$ & $<0.001$ & $1.87(0.98-3.85)$ & 0.089 \\
\hline Absent & 1.0 (reference) & & 1.0 (reference) & \\
\hline \multicolumn{5}{|l|}{ Thrombophilia } \\
\hline Inherited and/or acquired & $0.58(0.34-0.99)$ & 0.007 & $1.03(0.50-2.12)$ & 0.80 \\
\hline MPD or JAK2 mutationt & $1.18(0.70-1.98)$ & & $1.20(0.61-2.35)$ & \\
\hline Other & 1.0 (reference) & & 1.0 (reference) & \\
\hline Bilirubin level (per 10-mmol/L increase) & $1.05(1.02-1.09)$ & $<0.001$ & $1.03(0.98-1.08)$ & 0.24 \\
\hline Albumin level (per 1-g/L increase) & $0.95(0.93-0.97)$ & $<0.001$ & $0.97(0.94-1.00)$ & 0.078 \\
\hline Prothrombin time (per 1-unit increase in INR) $\neq$ & $1.23(1.07-1.42)$ & $<0.001$ & $1.02(0.81-1.28)$ & 0.88 \\
\hline ALT level (per 1-unit increase in ULN) & $1.01(1.01-1.02)$ & $<0.001$ & $1.01(1.00-1.01)$ & 0.124 \\
\hline Creatinine level (per 10-mmol/L increase) & $1.06(1.04-1.08)$ & $<0.001$ & $1.06(1.02-1.09)$ & 0.001 \\
\hline
\end{tabular}

ALT $=$ alanine aminotransferase; INR $=$ international normalized ratio; MPD $=$ myeloproliferative disorder; ULN $=$ upper limit of normal.

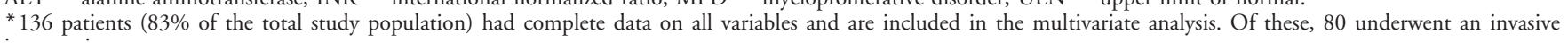
intervention.

† Includes patients with only MPD and the JAK2 mutation $(n=18)$ or in combination with inherited or acquired thrombophilia $(n=36)$.

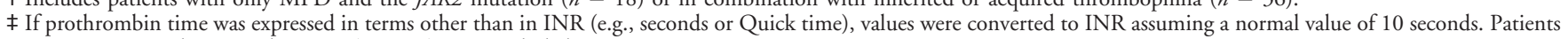
receiving anticoagulation at diagnosis $(n=20)$ were excluded. 
ARTICLE Etiology, Management, and Outcome of the Budd-Chiari Syndrome

and less invasive procedures (such as TIPS), which were not commonly used in the past, probably also contribute to the observed improvement in survival.

Our study has limitations. First, because the enrollment period was long, follow-up time varied greatly. The decision to extend the enrollment period at the expense of the follow-up period to include a larger number of patients was supported by data from several previous studies, which showed that the majority of events (such as death, OLT, and other treatments) occur in the first 6 months to 1 year after diagnosis $(8-10,25)$. Extending the follow-up period would probably not have resulted in gain of crucial information. Second, most patients underwent a complete work-up for thrombophilia, primarily because anticoagulation given before or immediately after diagnosis limited our ability to perform accurate tests in everyone. Third, data on key clinical variables were missing for many patients. Finally, because the study was observational, treatment allocation could not be standardized among all participating centers.

In conclusion, our case series suggests that thrombophilias, and MPDs in particular, are very common in patients with BCS. On the basis of these findings, we believe that a complete work-up for thrombophilia is warranted, including screening for MPD, and that the work-up should not stop after identification of a single cause, because almost half of patients have more than 1 underlying disorder. Our study also suggests that patients with BCS have excellent 1- and 2-year survival rates when they are managed with anticoagulation and TIPS, with OLT as a salvage procedure. Finally, surgical shunting, which was the treatment of choice a decade ago, seems to have lost its place in the contemporary management of BCS.

From Erasmus MC University Hospital Rotterdam, Rotterdam, and Leiden University Medical Center, Leiden, the Netherlands; Hôpital Beaujon, AP-HP, INSERM U773, and Université Denis Diderot-Paris 7, Clichy, France; Hospital Clinic, IDIBAPS and Ciberehd, Barcelona, Spain; IRCCS Maggiore Hospital, Mangiagalli and Regina Elena Foundation, Milan, Italy; Queen Elizabeth Hospital Birmingham, Birmingham, United Kingdom; Hannover Medical School, Hannover, and University Hospital of Bonn, University of Bonn, Bonn, Germany; Geneva University Hospitals, Geneva, Switzerland; Centre Hospitalier Universitaire Brugmann, Brussels, Belgium; and Hospital General Santo Antonio, Porto, Portugal.

Acknowledgment: The authors thank the study investigators, without whom this study would have not been possible, and the study participants.

Grant Support: The EN-Vie project was financially supported by the Fifth Framework Programme of the European Commission (contract QLG1-CT-2002-01686) and public funding from GIS Maladies Rares (France 2001). Dr. Darwish Murad is a Mosaic Laureate of the Netherlands Organization for Scientific Research. Dr. Janssen is a Clinical Fellow and VIDI laureate of the Netherlands Organization for Scientific Research. Ciberehd is funded by Instituto de Salud Carlos III.

Potential Financial Conflicts of Interest: None disclosed.
Reproducible Research Statement: Study protocol: Available from Dr. Janssen (e-mail, h.janssen@erasmusmc.nl). Statistical code: Not available. Data set: Available in a limited fashion to approved individuals with a relevant research proposal by contacting Dr. Janssen (e-mail, h.janssen @erasmusmc.nl).

Requests for Single Reprints: Harry L.A. Janssen, MD, PhD, Department of Gastroenterology and Hepatology, Erasmus MC University Hospital Rotterdam, 's Gravendijkwal 230, 3015 CE Rotterdam, the Netherlands; e-mail, h.janssen@erasmusmc.nl.

Current author addresses and author contributions are available at www .annals.org.

\section{References}

1. Ludwig J, Hashimoto E, McGill DB, van Heerden JA. Classification of hepatic venous outflow obstruction: ambiguous terminology of the Budd-Chiari syndrome. Mayo Clin Proc. 1990;65:51-5. [PMID: 2296212]

2. Denninger MH, Chaït Y, Casadevall N, Hillaire S, Guillin MC, Bezeaud A, et al. Cause of portal or hepatic venous thrombosis in adults: the role of multiple concurrent factors. Hepatology. 2000;31:587-91. [PMID: 10706547]

3. Janssen HL, Meinardi JR, Vleggaar FP, van Uum SH, Haagsma EB, van Der Meer FJ, et al. Factor V Leiden mutation, prothrombin gene mutation, and deficiencies in coagulation inhibitors associated with Budd-Chiari syndrome and portal vein thrombosis: results of a case-control study. Blood. 2000;96:2364-8. [PMID: 11001884]

4. Janssen HL, Garcia-Pagan JC, Elias E, Mentha G, Hadengue A, Valla DC; European Group for the Study of Vascular Disorders of the Liver. Budd-Chiari syndrome: a review by an expert panel. J Hepatol. 2003;38:364-71. [PMID: 12586305]

5. Valla DC. The diagnosis and management of the Budd-Chiari syndrome: consensus and controversies. Hepatology. 2003;38:793-803. [PMID: 14512865] 6. Valla DC. Hepatic venous outflow tract obstruction etipathogenesis: Asia versus the West. J Gastroenterol Hepatol. 2004;19:S204-11. Accessed at http://pt.wkhealth .com/pt/re/jgah/abstract.00001753-200412007-00032.htm jsessionid $=$ KZ3T2wL12yShWLSLvygBCrcVRn1nvTD7w4HTcXsvRBgG0RR4wsvL!1775402713 !181195628!8091!-1 on 9 June 2009.

7. Hadengue A, Poliquin M, Vilgrain V, Belghiti J, Degott C, Erlinger S, et al. The changing scene of hepatic vein thrombosis: recognition of asymptomatic cases. Gastroenterology. 1994;106:1042-7. [PMID: 8143970]

8. Murad SD, Valla DC, de Groen PC, Zeitoun G, Hopmans JA, Haagsma $\mathrm{EB}$, et al. Determinants of survival and the effect of portosystemic shunting in patients with Budd-Chiari syndrome. Hepatology. 2004;39:500-8. [PMID: 14768004]

9. Plessier A, Sibert A, Consigny Y, Hakime A, Zappa M, Denninger MH, et al. Aiming at minimal invasiveness as a therapeutic strategy for Budd-Chiari syndrome. Hepatology. 2006;44:1308-16. [PMID: 17058215]

10. Zeitoun G, Escolano S, Hadengue A, Azar N, El Younsi M, Mallet A, et al. Outcome of Budd-Chiari syndrome: a multivariate analysis of factors related to survival including surgical portosystemic shunting. Hepatology. 1999;30:84-9. [PMID: 10385643]

11. Langlet P, Escolano S, Valla D, Coste-Zeitoun D, Denie C, Mallet A, et al. Clinicopathological forms and prognostic index in Budd-Chiari syndrome. J Hepatol. 2003;39:496-501. [PMID: 12971957]

12. Smalberg JH, Murad SD, Braakman E, Valk PJ, Janssen HL, Leebeek FW. Myeloproliferative disease in the pathogenesis and survival of Budd-Chiari syndrome [Letter]. Haematologica. 2006;91:1712-3. [PMID: 17145613]

13. Valla D, Casadevall N, Lacombe C, Varet B, Goldwasser E, Franco D, et al. Primary myeloproliferative disorder and hepatic vein thrombosis. A prospective study of erythroid colony formation in vitro in 20 patients with Budd-Chiari syndrome. Ann Intern Med. 1985;103:329-34. [PMID: 4026081]

14. Chait Y, Condat B, Cazals-Hatem D, Rufat P, Atmani S, Chaoui D, et al. Relevance of the criteria commonly used to diagnose myeloproliferative disorder in patients with splanchnic vein thrombosis. Br J Haematol. 2005;129:553-60. [PMID: 15877740]

15. Patel RK, Lea NC, Heneghan MA, Westwood NB, Milojkovic D, Thanigaikumar M, et al. Prevalence of the activating JAK2 tyrosine kinase mutation 
V617F in the Budd-Chiari syndrome. Gastroenterology. 2006;130:2031-8. [PMID: 16762626]

16. Primignani M, Barosi G, Bergamaschi G, Gianelli U, Fabris F, Reati R, et al. Role of the JAK2 mutation in the diagnosis of chronic myeloproliferative disorders in splanchnic vein thrombosis. Hepatology. 2006;44:1528-34. [PMID: 17133457]

17. Deltenre P, Denninger MH, Hillaire S, Guillin MC, Casadevall N, Brière J, et al. Factor V Leiden related Budd-Chiari syndrome. Gut. 2001;48:264-8. [PMID: 11156651]

18. Mahmoud AE, Wilde JT, Elias E. Budd-Chiari syndrome and factor V Leiden mutation [Letter]. Lancet. 1995;345:526. [PMID: 7861905]

19. Koster T, Rosendaal FR, de Ronde H, Briët E, Vandenbroucke JP, Bertina $\mathrm{RM}$. Venous thrombosis due to poor anticoagulant response to activated protein C: Leiden Thrombophilia Study. Lancet. 1993;342:1503-6. [PMID: 7902898] 20. Ridker PM, Hennekens CH, Lindpaintner K, Stampfer MJ, Eisenberg PR, Miletich JP. Mutation in the gene coding for coagulation factor $\mathrm{V}$ and the risk of myocardial infarction, stroke, and venous thrombosis in apparently healthy men.
N Engl J Med. 1995;332:912-7. [PMID: 7877648]

21. Rees DC, Cox M, Clegg JB. World distribution of factor V Leiden. Lancet. 1995;346:1133-4. [PMID: 7475606]

22. Poort SR, Rosendaal FR, Reitsma PH, Bertina RM. A common genetic variation in the $3^{\prime}$-untranslated region of the prothrombin gene is associated with elevated plasma prothrombin levels and an increase in venous thrombosis. Blood. 1996;88:3698-703. [PMID: 8916933]

23. Gandini R, Konda D, Simonetti G. Transjugular intrahepatic portosystemic shunt patency and clinical outcome in patients with Budd-Chiari syndrome: covered versus uncovered stents. Radiology. 2006;241:298-305. [PMID: 16908675]

24. Hernández-Guerra M, Turnes J, Rubinstein P, Olliff S, Elias E, Bosch J, et al. PTFE-covered stents improve TIPS patency in Budd-Chiari syndrome. Hepatology. 2004;40:1197-202. [PMID: 15486923]

25. Tang TJ, Batts KP, de Groen PC, van Hoek B, Haagsma EB, Hop WC, et al. The prognostic value of histology in the assessment of patients with BuddChiari syndrome. J Hepatol. 2001;35:338-43. [PMID: 11592594]

\section{ICMJe Seeking 2 New Member Journals}

The International Committee of Medical Journal Editors (ICMJE) is seeking 2 new member journals to be represented by their editors-in-chief. Information about the ICMJE is available at www.icmje.org. The ICMJE anticipates selection of new members by 1 November 2009. Candidate journals should meet the following criteria:

- peer-reviewed, general medical journal

- represent geographic areas (Latin America, Asia, Africa) or publication models (open access) not well represented by current ICMJE members

- editor who is knowledgeable about publication ethics

- editor who expects to be in the position for at least 3 years

To apply, editors-in-chief of interested journals should send electronic copies of the following to the ICMJE secretariat (Christine Laine at claine@acponline.org) by September 1:

- brief curriculum vitae

- description of journal (age, sponsor/publisher, publishing model [including subscription model, author pays, and open-access policy], target audience, circulation, number of manuscript submissions/year, description of peer-review process used to select material for publication, acceptance rate, bibliographical databases where indexed, Web site address if applicable, copy of guidelines for authors)

- statement on why the journal/editor wants to be an ICMJE member (should not exceed 1000 words)

- contact information 
Current Author Addresses: Drs. Darwish Murad and Janssen: Department of Gastroenterology and Hepatology, Erasmus MC University Hospital Rotterdam, 's Gravendijkwal 230, 3015 CE Rotterdam, the Netherlands.

Drs. Plessier and Valla: Service d'Hépatologie, Hôpital Beaujon, AP-HP, INSERM U773, and Université Denis Diderot-Paris 7, 100 boulevard du général Leclerc, 92110 Clichy, France.

Dr. Hernandez-Guerra and Garcia-Pagan: Hepatic Hemodynamic Laboratory, Liver Unit, Hospital Clinic, IDIBAPS and Ciberehd, Carrer de Villarroel 170, 08036 Barcelona, Spain.

Dr. Fabris and Primignani: Gastroenterology Unit, IRCCS Maggiore Hospital, Mangiagalli and Regina Elena Foundation, Via Pace 9, I-20122 Milan, Italy.

Drs. Eapen and Elias: Liver Unit, Queen Elizabeth Hospital Birmingham, Metchley Park Road, Edgbaston, B15 2TH Birmingham, United Kingdom.

Dr. Bahr: Department of Gastroenterology, Hepatology, and Endocrinology, Hannover Medical School, Carl Neuberg Strasse 1, D-30623 Hannover, Germany.

Drs. Trebicka and Heller: Department of Internal Medicine I, University Hospital of Bonn, University of Bonn, Sigmund-Freud-Strasse 25, D-53105 Bonn, Germany.

Drs. Morard and Hadengue: Division of Gastroenterology and Hepatology, Geneva University Hospitals, 24 rue Micheli-du-Crest, CH-1211 Geneva, Switzerland.

Drs. Lasser and Langlet: Department of Hepatogastroenterology, Centre Hospitalier Universitaire Brugmann, Place Van Gehuchten 4, B-1020 Brussels, Belgium.

Dr. Miranda: Liver Transplantation Unit, Hospital General Santo Antonio, Largo Abel Salazar, P-4090-001, Porto, Portugal.

Dr. Leebeek: Department of Hematology, Erasmus University Medical Center Rotterdam, 's Gravendijkwal 230, 3015 CE Rotterdam, the Netherlands.

Dr. Rosendaal: Department of Clinical Epidemiology and Department of Thrombosis and Haemostasis, Leiden University Medical Center, Albinusdreef 2, 2333 ZA Leiden, the Netherlands.

Author Contributions: Conception and design: S. Darwish Murad, A. Plessier, F. Fabris, M.J. Bahr, A. Hadengue, M. Primignani, E. Elwyn, F.R. Rosendaal, J.C. Garcia-Pagan, D.C. Valla, H.L.A. Janssen.

Analysis and interpretation of the data: S. Darwish Murad, A. Plessier, C.E. Eapen, M.J. Bahr, J. Trebicka, A. Hadengue, E. Elwyn, F.W. Leebeek, J.C. Garcia-Pagan, D.C. Valla, H.L.A. Janssen.

Drafting of the article: S. Darwish Murad, A. Plessier, E. Elwyn, J.C. Garcia-Pagan, H.L.A. Janssen.

Critical revision of the article for important intellectual content: A. Plessier, F. Fabris, M.J. Bahr, J. Trebicka, J. Heller, M. Primignani, E. Elwyn, F.W. Leebeek, F.R. Rosendaal, J.C. Garcia-Pagan, D.C. Valla, H.L.A. Janssen.

Final approval of the article: A. Plessier, F. Fabris, M.J. Bahr, J. Heller, M. Primignani, E. Elwyn, F.W. Leebeek, F.R. Rosendaal, J.C. GarciaPagan, D.C. Valla, H.L.A. Janssen.

Provision of study materials or patients: S. Darwish Murad, A. Plessier, M. Hernandez-Guerra, F. Fabris, C.E. Eapen, M.J. Bahr, L. Lasser, J. Heller, P. Langlet, H. Miranda, M. Primignani, E. Elwyn, F.W. Leebeek, H.L.A. Janssen.

Statistical expertise: S. Darwish Murad, A. Plessier, F.R. Rosendaal, J.C. Garcia-Pagan, H.L.A. Janssen.

Obtaining of funding: M.J. Bahr, H. Miranda, E. Elwyn, J.C. GarciaPagan, H.L.A. Janssen.

Administrative, technical, or logistic support: S. Darwish Murad, A. Plessier, M.J. Bahr, H.L.A. Janssen.
Collection and assembly of data: S. Darwish Murad, A. Plessier, M. Hernandez-Guerra, F. Fabris, C.E. Eapen, M.J. Bahr, J. Trebicka, I. Morard, L. Lasser, J. Heller, P. Langlet, H. Miranda, M. Primignani, J.C. Garcia-Pagan, H.L.A. Janssen.

\section{Appendix: The EN-Vie InVestigators}

Belgian Network for Vascular Liver Disorders: N. Bourgeois (Hôpital ERASME, Brussels), J. Dewaide (Centre Hospitalier Universitaire [CHU] Sart Tilman, Liège), P. Gruselle (CHU Vésale, Charleroi), J.P. Martinet (Clinique Universitaire MontGodinne, Yvoir).

British Network for Vascular Liver Disorders: J. O'Grady (King's College Hospital, London), A. Burroughs, D. Patch (Royal Free Hospital, London), A. McGilchrist (Royal Infirmary, Edinburgh), G. Thomas (University Hospital of Wales, Cardiff), J. Swift (Llandough Hospital, Penarth), T. Higginson (Portsmouth Hospital, Portsmouth), M.H. Davies (St. James University Hospital, Leeds), S. Kapaida (New Cross Hospital, Wolverhampton), S. Catnach (St. Albans City Hospital, St. Albans).

Dutch Network for Vascular Liver Disorders: F.W.G. Leebeek, W.C.M Tielemans, D.C. Rijken, H.R. van Buuren, H.J. Metselaar, R.A. de Man, J.J.M.C. Malfliet, A. Keizerwaard, L.A. van Santen, B. Hansen (Erasmus Medical Center, Rotterdam), M.N. Apericio-Pages (Ziekenhuis Rijnstate, Arnhem), K.J. van Erpecum (Univerisity Medical Center Utrecht, Utrecht), K. van der Linde (Medical Center Leeuwarden, Leeuwarden), C.M.J. van Nieuwkerk, E.T.T.L. Tjwa (VU University Medical Center, Amsterdam), R.J. Lieverse (Gelre Ziekenhuis, Amersfoort), R.J.Th. Ouwendijk, D.J. Bac (Ikazia Ziekenhuis, Rotterdam).

French Network for Vascular Liver Disorders: M. Achahboun, A. Marot, F. Durand, V. Vilgrain, D. Cazals-Hatem, D. Videau, M.H. Deninger, J. Belghitti (CHU Hôpital Beaujon, Clichy), B. Condat (Hôpital Saint-Camille, Bry-sur-Marne), C. Bureau (CHU Purpan, Toulouse), C. Chagneau-Derrode (CHU La Millétrie, Poitiers), O. Goria (CHU Charles Nicole, Rouen), S. Hillaire (CH Foch, Suresnes), J.B. Nousbaum (CHU La Cavale Blanche, Brest), M.T. Dao (CHU Côte de Nacre, Caen), L. D’Alterroche (CHU Hôpital Trousseau, Tours); Dr. P. Lebray (CHU La Pitié, Paris), Dr. Sondag (Centre Hospitalier, Mulhouse), C. De Kerguenec (Centre Hospitalier, Saint Denis), A. Rosenbaum (Hôpital Privé d'Antony, Antony), E. Bartoli (CHU Hôpital Nord, Amiens), F. Habersetszer (Hôpital Civil, Strasbourg), P. Mathurin (Hôpital Huriez, Lille), J.Y. Scoazec (CHU Hôtel-Dieu, Lyon), P. Marteau (CHU Lariboisière, Paris), C. Buffet (CHU de Bicêtre, Paris).

German Network for Vascular Liver Disorders: M. Rossle (University of Freiburg, Freiburg).

Italian Network for Vascular Liver Disorders: G. Minoli, G. Spinzi (Ospedale Valduce, Como), C. Boschetti, A. Dell'Era, A. Nicolini (IRCCS Ospedale Maggiore, Mangiagalli and Regina Elena Foundation, Milan), F. Marra, F. Vizzutti (A.O. Careggi, Firenze), A. De Santis (Policlinico Umberto I Roma, Rome), A. Berzigotti, M. Zoli (A.O. Sant'Orsola-Malpighi Bologna, Bologna), L. Bellis, C. Puoti (Ospedale Civile, Marino).

Spanish Network for Vascular Liver Disorders: R. Lozano, F. Geva, J.G. Abraldes, J. Bosch, F. Cervantes, J.C. Reverter, J.R. 
Ayuso, R. Gilabert, A. Garcia-Criado, J. Fuster, R. Saez, A. Baringo, L. Rocabert (Hospital Clinic, Barcelona), D. Suarez Sambade (Centro Hospitalario Arquitecto Marcide, Ferrol), M. Fernández-Bermejo (Hospital San Pedro de Alcántara, San Pedro de Alcántara), M. Berenguer, V. Aguillera (Hospital Universitario La Fe, Valencia), M. de la Mata (Hospital Reina Sofia, Córdoba), J. Bustamante (Hospital de Cruces, Cruces/Barakaldo), R. Bañares Cañizares, O. Nuñez (Hospital General Universitario Gregorio Marañon, Madrid), A. Monescillo (Hospital Universitario In- sular, Gran Canaria), P. Sánchez-Pobre (Hospital Universitario "12 de Octubre," Madrid), J. Fernandez Castroagudin (Hospital Clinico, Universitario, Santiago), M. Vergara Gomez (Corporacio Sanitaria Parc Tauli, Sabadell), P. Fernández-Gil (Hospital Comarcal, Sierrallana), J.L. Lledo Navarro (Hospital Universitario Fundación Alcorcón, Madrid), F. Pons (Hospital Rio Hortega, Valladolid), M. Romero (Hospital Universitario Valme, Sevilla), L. Viladomiu (Hospital Vall d'Hebron, Barcelona). 